\title{
Primary Pineal Yolk Sac Tumor: Ultrastructural and Immunohistochemical Features
}

\author{
-Case Report- \\ Shunji Nishio, Masashi FukUI, Toru IWAKI*, \\ Takato MORIOKA and Katsutoshi KITAMURA \\ Departments of Neurosurgery and ${ }^{*}$ Neuropathology, Neurological Institute, \\ Faculty of Medicine, Kyushu University, Fukuoka
}

\begin{abstract}
In an autopsy of a 16-year-old female with a primary intracranial yolk sac tumor (endodermal sinus tumor), histological evaluation of the surgical specimen obtained from the pineal region showed proliferation of undifferentiated neoplastic embryonal cells without characteristic histological features, such as periodic acid-Schiff-positive hyaline droplets or Schiller-Duval bodies. Ultrastructural study of the tumor cells, however, revealed typical cytological features of yolk sac tumor, including a voluminous, homogeneous, basement membrane-like substance, both within and outside of the cells, and intracytoplasmic vesicles containing amorphous material. Alpha-fetoprotein was detected in serum and cerebrospinal fluid by radioimmunoassay and within tumor tissues by immunohistochemical techniques. After surgery, chemotherapy with cis-diamminedichloroplatinum (II), vinblastine, and bleomycin was employed without significant benefit, and the patient died 5 months after tumor removal. Histological examination of the tumor at autopsy supported the diagnosis of yolk sac tumor. Electron microscopic and immunohistochemical studies of germ cell tumors are discussed.
\end{abstract}

Key word: yolk sac tumor, pineal region, alpha-fetoprotein, ultrastructure, immunohistochemistry

\section{Introduction}

Yolk sac tumor, or endodermal sinus tumor, is a peculiar germ cell tumor that mimics normal yolk sac structures. This tumor was initially described and defined by Teilum, ${ }^{30)}$ who characterized it as a gonadal neoplasm. However, like other types of germ cell tumor, it may also arise in extragonadal sites, such as sacrococcygeal, mediastinal, or retroperitoneal regions, liver, or vagina. ${ }^{11,197}$ Primary intracranial yolk sac tumors have also been reported in the suprasellar and pineal regions. $1,2,6,10.13,14,23,28,36,38\}$ We will describe ultrastructural and immunohistochemical findings in a rare neoplasm, a primary intracranial yolk sac tumor originating in the pineal region.

Received July 24, 1985; Accepted February 28,

\section{Case Report}

A 15-year-old Japanese female had been in good health until April, 1981, when she began to experience double vision, headache, and vomiting in the early mornings. She was admitted to a hospital in June, 1981. Neurological examination revealed bilateral papilledema and Parinaud's sign. No other physical or neurological abnormalities were noted. Computerized tomography (CT) disclosed symmetrically dilated lateral ventricles and a pineal tumor, which was markedly enhanced after administration of contrast medium. The levels of serum and lumbar cerebrospinal fluid (CSF) alpha-fetoprotein (AFP) were $10,000 \mathrm{ng} / \mathrm{ml}$ and $4,100 \mathrm{ng} / \mathrm{ml}$, respectively. She underwent ventriculo-peritoneal shunt and irradiation to the pineal region, in a cumulative dose of 6,075 rads. After this treatment her symptoms disappeared, except for a persistent, mild upward gaze palsy. The serum AFP fell to $4,200 \mathrm{ng} / \mathrm{ml}$ and a $C T$ scan revealed a slight reduction in the 
tumor size and disappearance of contrast enhancement. However, a follow-up CT scan demonstrated rapid regrowth of the tumor and reappearance of contrast enhancement.

On October 22, 1981, she was admitted to Kyushu University Hospital for surgical removal and chemotherapy of the tumor. Although alert and welloriented, she exhibited bilateral sluggish pupillary response to light, bilateral mydriasis, upward gaze palsy with convergent nystagmus, and right abducens palsy. The levels of AFP in serum and lumbar and ventricular CSF were $3,534 \mathrm{ng} / \mathrm{ml}, 8,490 \mathrm{ng} / \mathrm{ml}$, and $19,300 \mathrm{ng} / \mathrm{ml}$, respectively. Direct surgery was performed through the infratentorial supracerebellar route on November 24,1981 . The bulk of the tumor in the third ventricle was removed, but the mass on the quadrigeminal plate was only partially removed.

After surgery, chemotherapy with cis-diamminedichloroplatinum (II) (cis-DDP), vinblastine (VBL), and bleomycin (BLM) was started. The AFP level in the ventricular CSF just before chemotherapy was $22,800 \mathrm{ng} / \mathrm{ml}$. In January, 1982 she gradually developed bilateral hearing difficulty. The AFP level in ventricular CSF on February 2, 1982 fell to 2,549 $\mathrm{ng} / \mathrm{ml}$. On March 11, 1982 the chemotherapy was completed, with total cumulative doses of $375 \mathrm{mg}$ of cis-DDP, $20 \mathrm{mg}$ of VBL, and $45 \mathrm{mg}$ of BLM. No clinical improvement occurred and she died on April $26,1982,5$ months after tumor removal, at the age of 16 years and 6 months. During the entire course of the disease, beta-human chorionic gonadotropin and carcinoembryonic antigen were both within the normal range in serum and lumbar CSF.

An autopsy was performed $21 / 2$ hours after death. The body, $166 \mathrm{~cm}$ in length and $33 \mathrm{~kg}$ in weight, was markedly cachectic. Other abnormalities were confined to the brain.

For histological examinations, both surgical specimens and autopsy materials were fixed in $10 \%$ buffered formalin. For immunohistochemical study, the peroxidase-antiperoxidase (PAP) method was used to demonstrate the presence of AFP in formalinfixed, paraffin-embedded surgical materials. For electron microscopic study, surgical specimens were fixed in $4 \%$ glutaraldehyde, postfixed in $2 \%$ osmium tetroxide, and embedded in Epon 812. Ultrathin sections were prepared on a Porter-Blum MT2B ultramicrotome, stained with uranyl acetate and lead citrate, and examined with a Hitachi HS-9 electron microscope.

\section{Surgical material}

Light microscopic findings: Tumor cells with prominent, round nuclei and large nucleoli were present

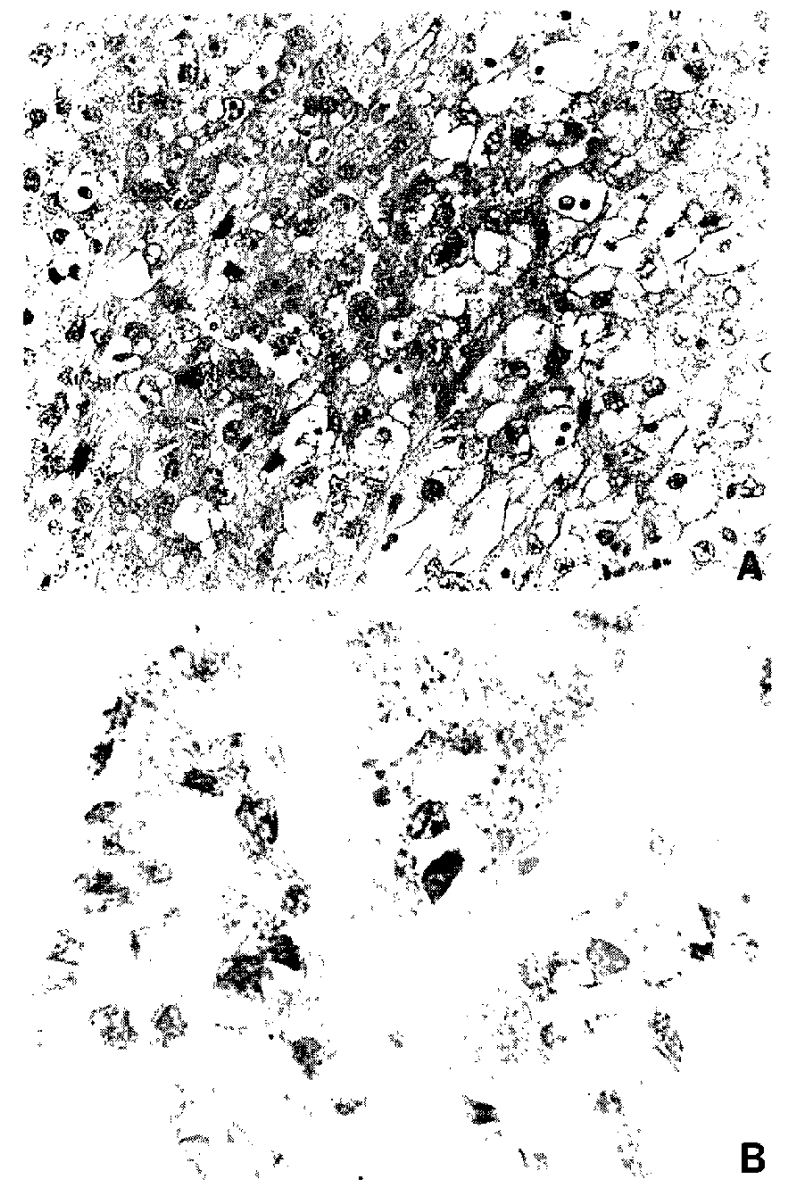

Fig. 1 Photomicrographs of the tumor obtained at surgery. A: Undifferentiated embryonal cells forming solid sheets. HE stain, $\times 260$. B: A tumor cell showing positive staining for AFP. PAP method, $\times 550$.

in solid sheets. The cytoplasm was abundant and homogeneously amphophilic or vacuolated (Fig. 1A). We did not find reticular, papillary, tubular, or acinar patterns of tumor cells; nor did we find giant cells or intra- or extracellular hyaline droplets. The tumor was diagnosed as embryonal carcinoma.

Immunohistochemical findings: Specific staining for AFP was observed in the cytoplasm of some tumor cells (Fig. 1B).

Electron microscopic findings: The tumor cells had uniform ultrastructural characteristics, except for some cells that showed degenerative changes. The euchromatic nuclei were oval or round (Fig. 2). Nucleoli were frequently observed and nucleolonema often had a thread-or skein-like appearance (Fig. $3 \mathrm{~A}$ ). The endoplasmic reticulum was abundant, and much of it was distended and contained flocculent material of moderate electron density. The rough en- 


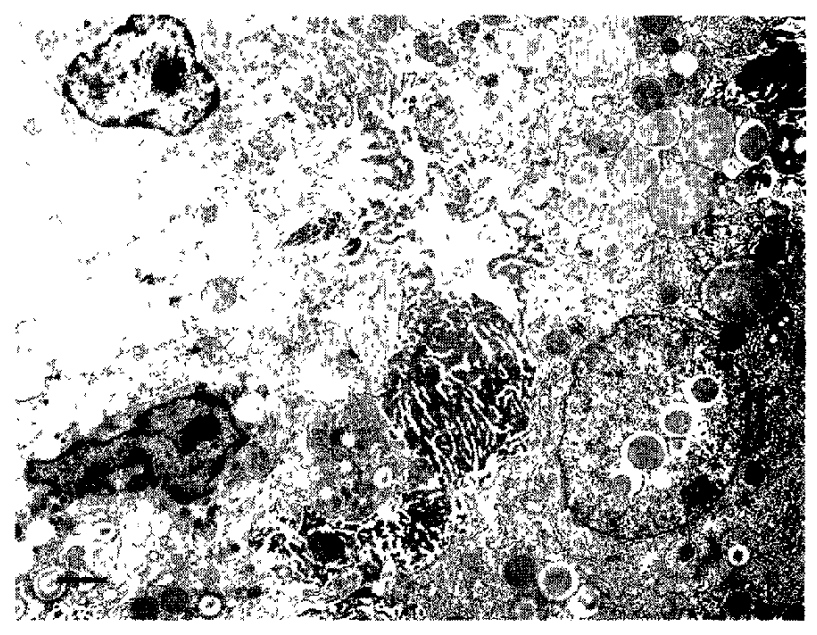

Fig. 2 Low-power electron micrograph showing numerous vesicles containing amorphous materials in both the cytoplasm and nuclei of tumor cells, and extracellular electron-dense "basement membrane-like materials." Note nuclear image. $\times 5,200, \mathrm{Bar}=2 \mu \mathrm{m}$.

doplasmic reticulum seemed to be associated closely with mitochondria in some areas (Fig. 3). Polysomes were distributed throughout the cytoplasm (Fig. 4). The mitochondria were round to oval (Fig. 3). Golgi apparatus were present but relatively inconspicuous, as were lysosome-like dense bodies. Many vesicles of variable size, containing amorphous material of moderate electron density, were observed in both the cytoplasm and the nuclei of the tumor cells (Figs. 24).

Voluminous deposits of electron-dense, amorphous material were found in both extra- and intracellular sites (Figs. 2 and 4). Occasionally this material also had a filamentous pattern (Fig. 5A) and partly blended with normally banded collagen fibers (Fig. 5B). This material surrounded tumor cells and also separated the small vessels from surrounding tumor cells (Fig. 6). The tumor cells were either closely attached to each other by desmosomes (Fig. 3B) or were separated by extracellular spaces containing this electron-dense material.

\section{Autopsy material}

Macroscopic findings: The brain weighed $1,350 \mathrm{~g}$. A huge tumor, $9 \times 6 \mathrm{~cm}$ in horizontal section, occupied the pineal region, the entire third ventricle, bilateral thalami, midbrain, corpus callosum, tegmentum of the pons, and fourth ventricle. The tumor was fairly firm in consistency and contained extensive necrotic and hemorrhagic areas.

Light microscopic findings: The tumor cells fre-

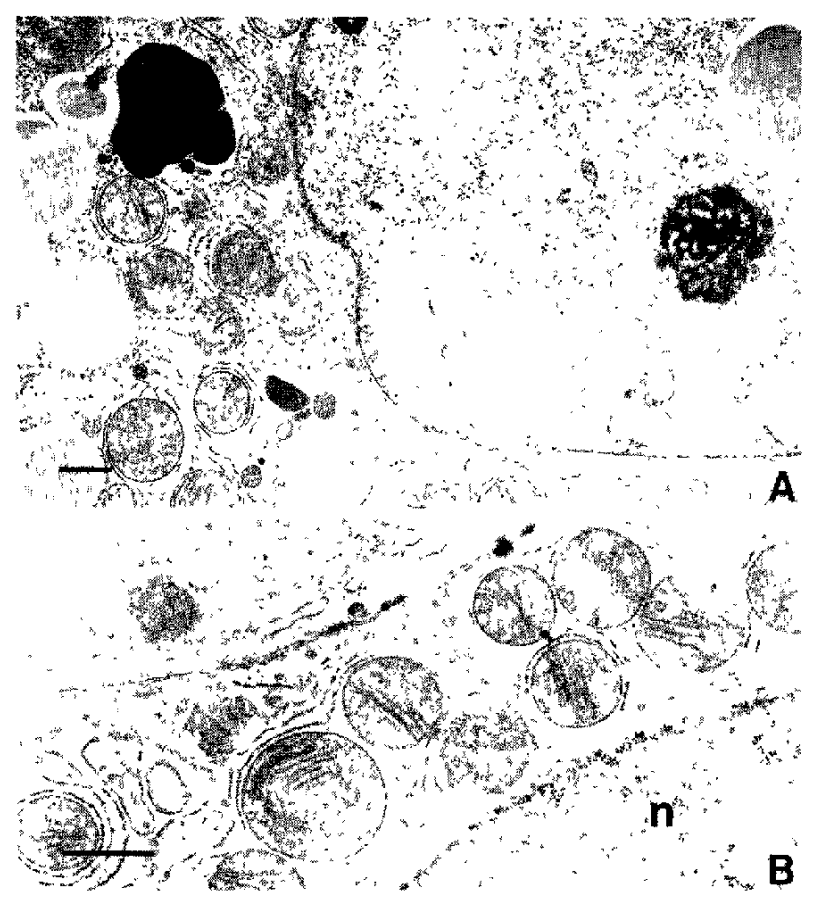

Fig. 3 High-power electron micrographs of tumor cells. A: A tumor cell with a euchromatic nucleus containing skein-like nucleolonema, round mitochondria, prominent rough endoplasmic reticulum, and many intracytoplasmic and intranuclear vesicles containing amorphous material. $\times 11,000$, Bar $=1 \mu \mathrm{m}$. B: Portion of the cytoplasm (top) and nucleus (n) of tumor cells with dilated rough endoplasmic reticulum and round mitochondria. Note the junctional complexes. $\times 19,000$, Bar $=1 \mu \mathrm{m}$.

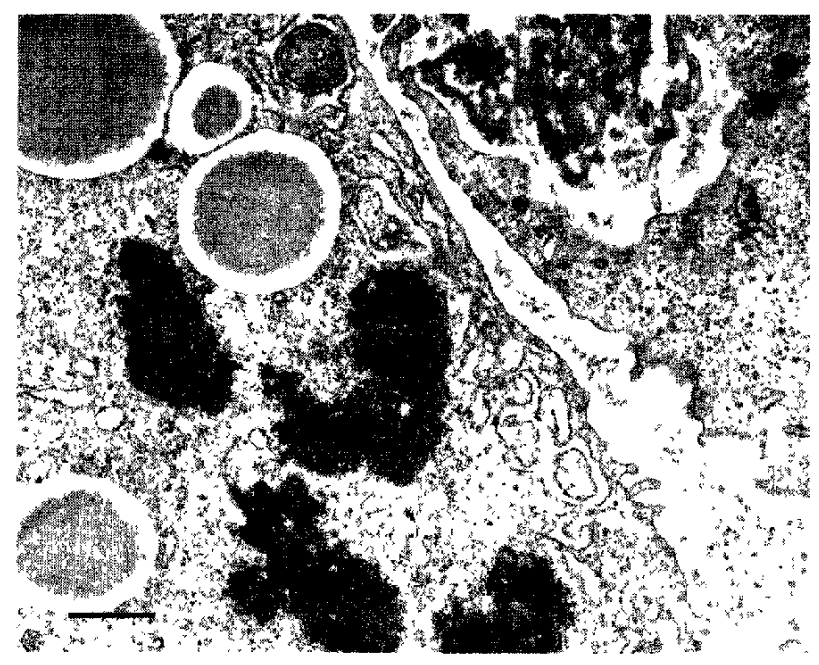

Fig. 4 The electron-dense "basement membrane-like materials" are found in both cytoplasm and intercellular spaces. $\times 18,000, \mathrm{Bar}=1 \mu \mathrm{m}$.

Neurol Med Chir (Tokyo) 26, July 1986 


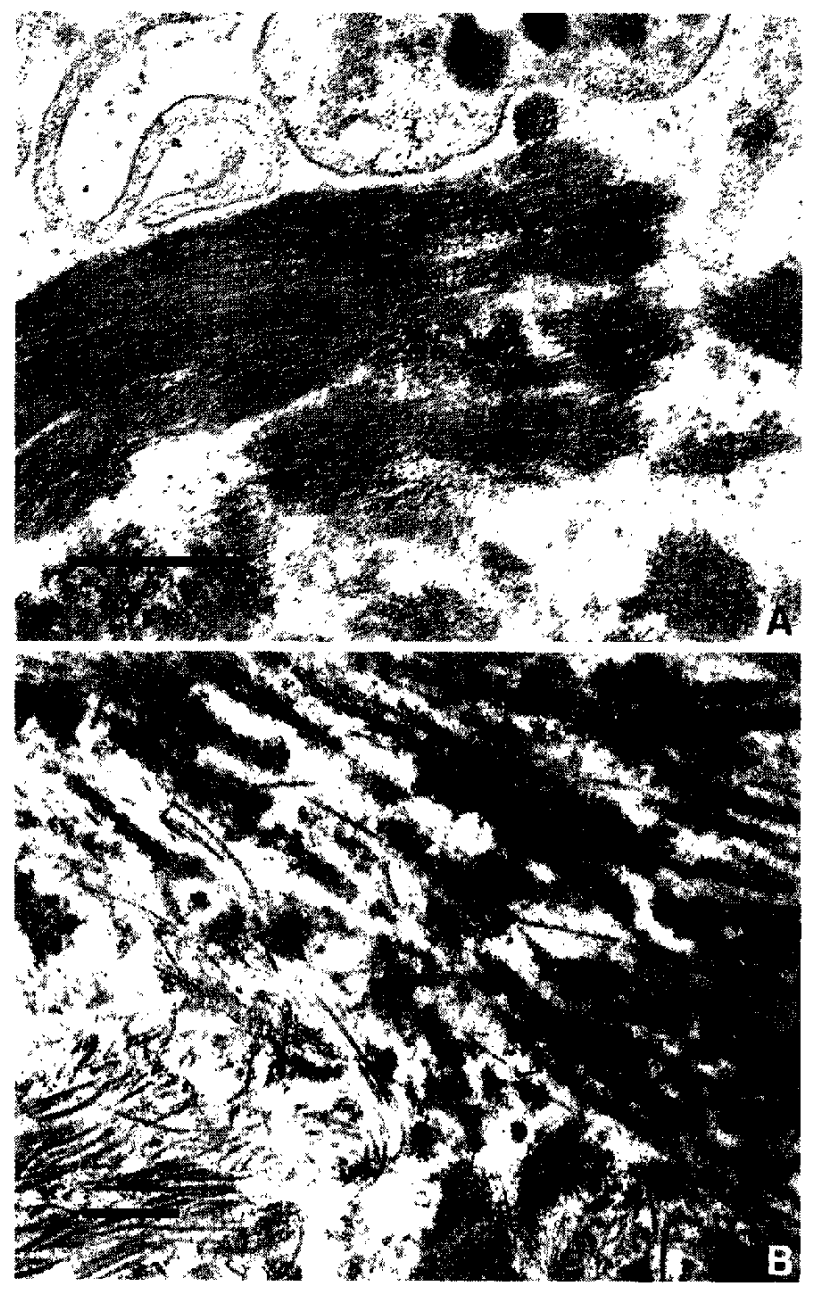

Fig. 5 Portions of the intercellular spaces of the tumor. A: The electron-dense filamentous material is found in the extracellular spaces. A long, slender cytoplasmic process protrudes into the intercellular space. $\times 37,000, \mathrm{Bar}=$ $0.5 \mu \mathrm{m}$. B: The electron-dense "basement membrane-like materials" are partly blended with collagen fibers. $\times 20,000, \mathrm{Bar}=0.5 \mu \mathrm{m}$.

quently formed irregular tubular or papillary structures (Fig. 7), though typical Schiller-Duval bodies were not present. We also noted microcysts arrayed in a honeycomb pattern and lined by short cuboidal tumor cells. periodic acid-Schiff (PAS)-positive hyaline droplets were numerous in both the cytoplasm and the extracellular spaces of the tumor cells (Fig. $7 B$ ). Tumor cells with prominent nucleoli and basophilic cytoplasm were also present, either in solid sheets or in a diffuse pattern. No other germ cell tumor elements, such as choriocarcinoma, germinoma, or teratoma, were evident. The diagnosis was yolk sac tumor with elements of embryonal carcinoma.

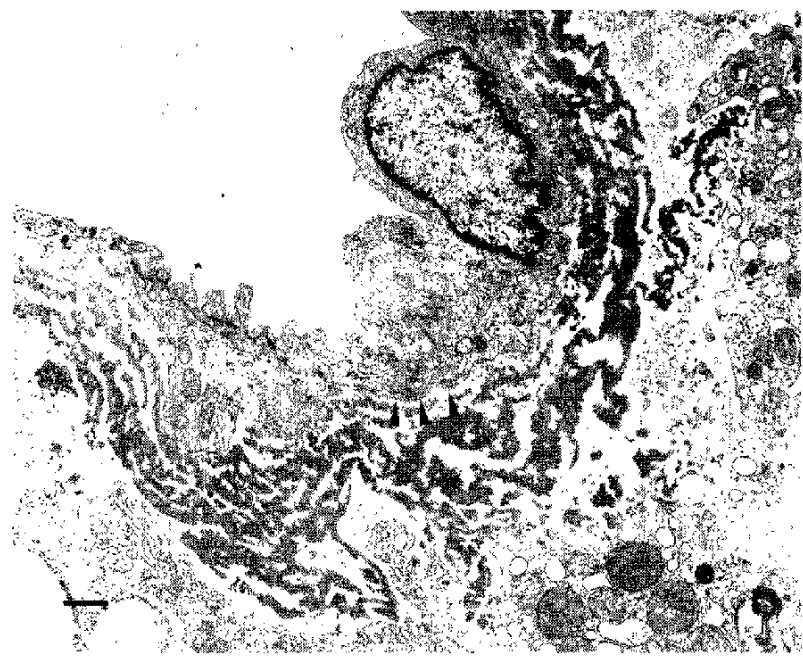

Fig. 6 Electron micrograph of a tumor vessel separated from tumor cells by a basement membrane of normal thickness (arrowheads) and markedly thickened "basement membrane-like materials." $\times 8,700, \mathrm{Bar}=1 \mu \mathrm{m}$.

\section{Discussion}

Yolk sac tumor is considered a highly malignant neoplasm of germ cell origin. ${ }^{27,301}$ Like gonadal yolk sac tumors, intracranial ones carry a poor prognosis, ${ }^{6.27)}$ and various treatments, including surgery, irradiation, chemotherapy, and different combinations of the three have been tried..$^{2,6,14,17)}$ Surgery has traditionally been limited to exploration and/or shunting, (6) and radiation therapy, too, has usually been palliative..$^{2,6)}$ For treatment of both gonadal and extragonadal germ cell tumors, cis-DDP has become widely used and has been reported to be effective..$^{520.351}$ Nakajima et al. ${ }^{151}$ reported a case of intracranial AFP-producing embryonal carcinoma successfully treated with combination chemotherapy comprising cis-DDP, VBL, and BLM. There are, however, certain problems with cis-DDP, such as the administration method and its various side effects. ${ }^{5,17,20.351}$ In our case, chemotherapy with cisDDP, VBL, and BLM produced no significant benefit.

Histological assessment rarely reveals a pure yolk sac tumor. Typically, admixtures of other types of germ cell tumors, such as germinoma, embryonal carcinoma, and choriocarcinoma are found. ${ }^{6,13.23,28)}$ According to Teilum's classification of germ cell tumors, ${ }^{31)}$ the totipotential stem cell of embryonal carcinoma may differentiate into yolk sac tumor, choriocarcinoma, teratoma, or any combination of these three types. Takei and Pearl, ${ }^{28)}$ on the other 


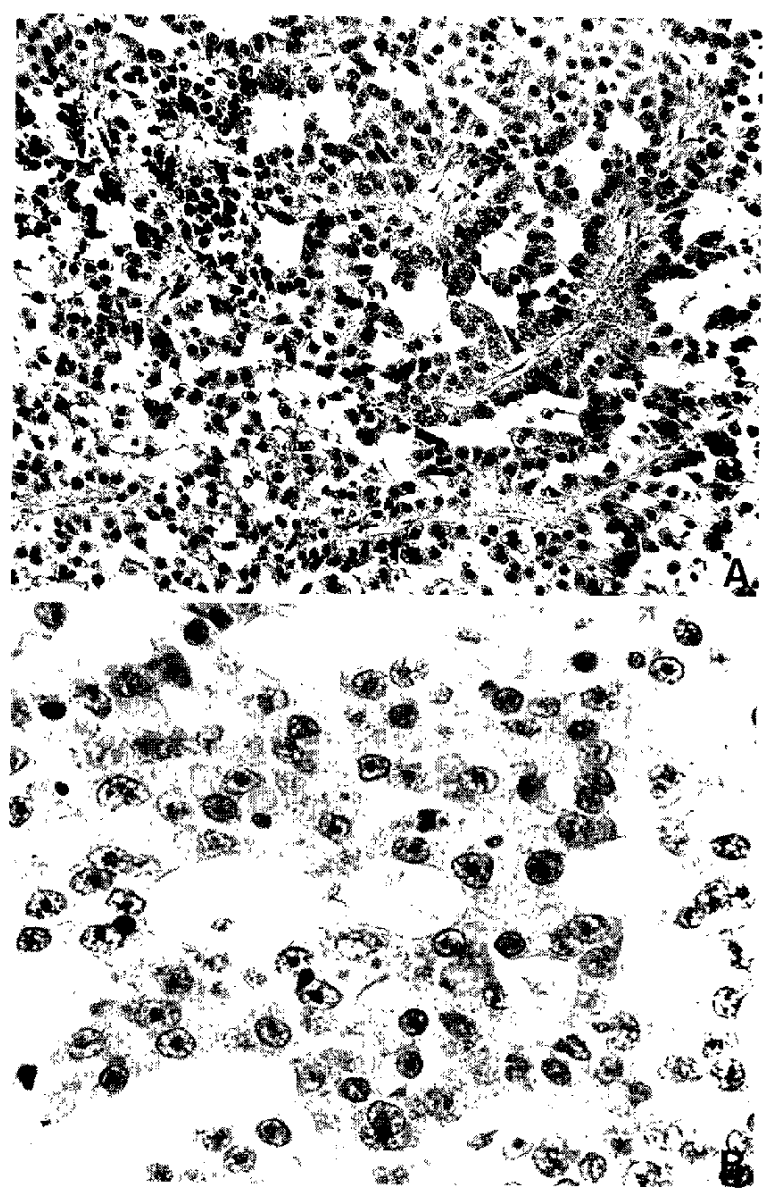

Fig. 7 Photomicrographs of the tumor obtained at autopsy. A: Papillary growth of tumor cells. HE stain, $\times 170$. B: Numerous intra- and extracellular hyaline globules and tubular structures of tumor cells. HE stain, $\times 400$.

hand, pointed out that embryonal carcinomas arise from overgrowth and rapid anaplasia of endodermal elements within yolk sac tumors. Although we could not draw definite conclusions concerning the direction of differentiation, our case contained both yolk sac tumor and embryonal carcinoma elements.

There have been several ultrastructural studies of yolk sac tumors of the gonads, ${ }^{4,8,19,24,26,37)}$ but only a few of intracranial yolk sac tumors. ${ }^{27,28)}$ A characteristic feature of ovarian, retroperitoneal, and sacrococcygeal yolk sac tumors ${ }^{4,8,19,37)}$ and of the normal human yolk $\mathrm{sac}^{8,19)}$ is the voluminous aggregates, both intra- and extracellular, of electrondense materials. These substances have been termed "basement membrane,"(9) "basement membranelike material," ${ }^{22)}$ and "iron-containing material."9) Intracranial yolk sac tumors also contain these characteristic deposits, ${ }^{27,28)}$ which have never been observed in any other types of germ cell tumors. ${ }^{191}$ The skein- or thread-like nucleolonema we observed in euchromatic nuclei of our patient's tumor cells is rarely seen in such abundance in tumors not derived from germ cells. ${ }^{19,21)}$ The tumor cells in this case had relatively inconspicuous Golgi apparatus, prominent rough endoplasmic reticulum, and fairly numerous free ribosomes, all of which are also characteristic of both gonadal and extragonadal yolk sac tumors and of normal human yolk sac. ${ }^{8,19\}}$

Our patient had high levels of AFP. Gitlin and Perricelli $^{7 /}$ demonstrated that synthesis of this protein is not confined to embryonic hepatocytes, but that it also takes place in the human yolk sac. In patients with gonadal and extragonadal germ cell tumors, the AFP level has been shown to be elevated only in the presence of tumors containing yolk sac tumor elements. ${ }^{2,12,18,19,34,38)}$ The clinical course of patients with intracranial yolk sac tumors has been reported to be closely correlated with AFP levels in serum and $\mathrm{CSF}, 2,3,6)$ and this was true in our case. Monitoring AFP levels in patients with this type of tumor is helpful in assessing the response to therapy, ${ }^{2,3,25,29,33)}$ estimating the tumor histopathology, and making a prognosis.

It has been demonstrated immunohistochemically that in yolk sac tumors AFP is present in both the tumor cell cytoplasm and the extracellular spaces. ${ }^{27,34)}$ Some authors ${ }^{16,32,38)}$ also noted that AFP resides in the extra- and intracellular PAS-positive hyaline globules, which are frequently found in yolk sac tumors and are of diagnostic importance. . $^{12,16,31,32,37\}}$ As these hyaline globules are considered to be the same as "basement membrane-like material," "8,19,37) presumably AFP may be present within this material. ${ }^{16,19,34)}$ However, others assert that AFP is located only in the intracytoplasmic hyaline globules ${ }^{16)}$ and in the cytoplasm of the tumor cells, either diffusely or as granules. ${ }^{2.141}$ Takei and Pearl ${ }^{281}$ claimed that electron microscopy revealed AFP within cytoplasmic membrane-bound vesicles containing amorphous material, which were also numerous in our patient's tumor. Further studies, using electron microscopic immunohistochemical techniques, are necessary for clarification of the precise location(s) of AFP.

Although in our case histological examination disclosed no apparent yolk sac tumor elements, such as PAS-positive hyaline globules or Schiller-Duval bodies, electron microscopy showed the tumor to have fine structural similarities to endodermal cells of yolk sac tumor. In addition to histopathological evaluation and measurement of AFP in serum and $\mathrm{CSF},{ }^{2,3,33,341}$ immunohistochemical determination of the presence of AFP and electron microscopic obser- 
vation of biopsy materials are helpful in making the diagnosis of germ cell tumor.

\section{References}

1) Albrechtsen R, Klee JG, Moller JE: Primary intracranial germ cell tumours including five cases of endodermal sinus tumour. Acta Path Microbiol Scand [Suppl] 233: 32-38, 1972

2) Arita $N$, Bitoh $S$, Ushio $Y$, Hayakawa $T$, Hasegawa $\mathrm{H}$, Fujiwara $M$, Ozaki $K$, Par-khen L, Mori $T$ : Primary pineal endodermal sinus tumor with elevated serum and CSF alphafetoprotein levels. $J$ Neurosurg 53: $244-248,1980$

3) Arita $N$, Ushio $Y$, Hayakawa $T$, Uozumi $T$, Watanabe M, Mori T, Mogami H: Serum levels of alpha-fetoprotein, human chorionic gonadotropin and carcinoembryonic antigen in patients with primary intracranial germ cell tumors. Oncodevel Biol Med 1: 235-240, 1980

4) Bocker $W$, Lietz $H$, Delling G: Endodermal sinus tumour of the ovary: A comparative light and electron microscopic study. Z Krebsforsch 86: 33-46, 1976

5) Bruckner HW, Cohen C J, Wallach RC, Kabakow B, Deppe G, Greenspan EM, Gusberg SB, Holland JH: Treatment of advanced ovarian cancer with cisdichlorodiammineplatinum (II): Poor-risk patients with intensive prior therapy. Cancer Treat Rep 62: $555-558,1978$

6) Eberts TJ, Ransburg RC: Primary intracranial endodermal sinus tumor. Case report. $J$ Neurosurg 50: 246-252, 1979

7) Gitlin D, Perricelli A: Synthesis of serum albumin, prealbumin, alpha-fetoprotein, alpha-1-antitrypsin and transferrin by the human yolk sac. Nature 228: 995-997, 1970

8) Gonzalez-Crussi F, Roth LM: The human yolk sac and yolk sac carcinoma. An ultrastructural study. Hum Pathol 7: 675-691, 1976

9) Hesseldahl H, Larsen JF: Ultrastructure of human yolk sac. Endoderm, mesenchyme, tubules and mesothelium. Am J Anat 126: 315-335, 1969

10) Ho KL, Rassekh ZS: Endodermal sinus tumor of the pineal region. Case report and review of the literature. Cancer 44: 1081-1086, 1979

11) Huntington RW Jr, Bullock WK: Yolk sac tumors of extragonadal origin. Cancer 25: 1368-1376, 1970

12) Itoh $T$, Shirai $T$, Naka A, Matsumoto S: Yolk sac tumor and $\alpha$-fetoprotein: Clinicopathological study of four cases. Gan 65: 215-226, 1974

13) Jellinger $\mathrm{K}$ : Primary intracranial germ cell tumors. Acta Neuropathol (Berl) 25: 291-306, 1973

14) Nakagawa $Y$, Okada M, Tanimoto K, Sogabe K, Matsumoto K, Furuya K: Primary endodermal sinus tumor of the fourth ventricle. No Shinkei Geka 8: 1177-1182, 1980 (in Japanese)

15) Nakajima F, Pak S, Fujitsu K, Kuwabara T: A case of alpha-fetoprotein producing primary intracranial embryonal carcinoma treated with combination chemotherapy of cis-platinum, vinblastine and bleomycin. No Shinkei Geka 9: 371-375, 1981 (in Japanese)

16) Nakanishi I, Kawahara E, Kajikawa K, Miwa A, Terahata S: Hyaline globules in yolk sac tumor. Histochemical, immunohistochemical and electron microscopic studies. Acta Pathol Jpn 32: 733-739, 1982

17) Nishio S, Ohnishi A, Fukui M, Tateishi J, Kitamura $\mathrm{K}$ : Peripheral nerve degeneration in a patient with pineal yolk sac tumor treated with cis-diamminedichloroplatinum (II). Rinsho Shinkeigaku 23: 655660, 1983 (in Japanese)

18) Nørgaard-Pedersen B, Lindholm J, Albrechtsen R, Arends J, Diemer NH, Riishede J: Alpha-fetoprotein and human chorionic gonadotropin in a patient with a primary intracranial germ cell tumor. Cancer 41: $2315-2320,1978$

19) Nogales-Fernandez F, Silverberg SG, Bloustein PA, Martinez-Hernandez A, Pierce GB: Yolk sac carcinoma (endodermal sinus tumor). Ultrastructure and histogenesis of gonadal and extragonadal tumors in comparison with normal human yolk sac. Cancer 39: 1462-1474, 1977

20) Ostrow S, Egorin MJ, Hahn D, Markus S, Leroy A, Chang P, Klein M, Bachur NR, Wiernik PH: Cisdichlorodiammineplatinum and adriamycin therapy for advanced gynecological and genitourinary neoplasms. Cancer 46: 1715-1721, 1980

21) Pierce GB: Ultrastructure of human testicular tumors. Cancer 19: 1963-1983, 1966

22) Pierce GB, Midgley AR Jr, Ram JS, Feldman JD: Parietal yolk sac carcinoma. Clue to the histogenesis of Reichert's membrane of the mouse embryo. Amer $J$ Path 41: 549-566, 1962

23) Rubinstein LJ: Cytogenesis and differentiation of pineal neoplasm. Hum Pathol 12: 441-448, 1981

24) Salazar H, Kanbour A, Tobon H, GonzalalesAngulo A: Endodermal cell derivatives in embryonal carcinoma of ovary: An electron microscopic study of two cases. Am J Pathol 74: 108, 1974 (abstract)

25) Schultz H, Sell A, Norgaard-Pedersen B, Arends J: Serum alpha-fetoprotein and human chorionic gonadotropin as markers for the effect of postoperative radiation therapy and/or chemotherapy in testicular cancer. Cancer 42: 2182-2186, 1978

26) Silverberg SG, Bloustein PA, Nogales FF: Endodermal sinus tumor of the ovary: An ultrastructural study. Lab Invest 32: 456, 1975 (abstract)

27) Stachura I, Mendelow H: Endodermal sinus tumor originating in the region of the pineal gland. Ultrastructural and immunohistochemical study. Cancer 45: 2131-2137, 1980

28) Takei Y, Pearl GS: Ultrastructural study of intracranial yolk sac tumor: With special reference to the oncologic phylogeny of germ cell tumors. Cancer 48 : 
2038-2046, 1981

29) Talerman A, Haije WG, Baggerman L: Serum alphafetoprotein (AFP) in diagnosis and management of endodermal sinus (yolk sac) tumor and mixed germ cell tumor of the ovary. Cancer 41: 272-278, 1978

30) Teilum G: Endodermal sinus tumors of the ovary and testis. Comparative morphogenesis of the so-called mesonephroma ovarii (Schiller) and extraembryonic (yolk sac-allantoic) structures of the rat's placenta. Cancer 12: 1092-1105, 1959

31) Teilum G: Classification of endodermal sinus tumours (mesoblastoma vittellium) and so-called "embryonal carcinoma" of the ovary. Acta Path Microbiol Scand 64: 407-429, 1965

32) Teilum G, Albrechtsen R, Norgaard-Pedersen B: Immunofluorescent localization of alpha-fetoprotein synthesis in endodermal sinus tumor (yolk sac tumor). Acta Pathol Microbiol Scand [A] 82: 586-588, 1974

33) Thompson DK, Haddow JE: Serial monitoring of serum alpha-fetoprotein and chorionic gonadotropin in males with germ cell tumors. Cancer 43: 18201829,1979

34) Tsuchiyama M, Miyamoto $M$, Sakurai M, Kitamura $\mathrm{H}$ : Intracranial germ cell tumor indicating a high level of alpha-fetoprotein (AFP). Acta Pathol Jpn 31: 521-526, 1981

35) Williams CJ, Whitehouse JMA: Cis-platinum: A new anticancer agent. Br Med J 1: 1689-1691, 1979

36) Wilson ER, Takei Y, Bikoff WT, O'Brien MS, Tindall GT, Boehm WM: Abdominal metastases of primary intracranial yolk sac tumors through ventriculoperitoneal shunts: Report of three cases. Neurosurgery 5: 356-364, 1979

37) Yoshida $M$, Murakami $M$, Nakajima $H$, Yamabe $T$ : Ultrastructure of endodermal sinus tumors of the ovary. Nippon Sanka Fujinka Gakkai Zasshi 32: 767-776, 1980 (in Japanese)

38) Yoshiki $T$, Itoh $T$, Shirai $T$, Noro $T$, Tomino $Y$, Hamajima I, Takeda T: Primary intracranial yolk sac tumor. Immunofluorescent demonstration of alphafetoprotein synthesis. Cancer 37: 2343-2348, 1976

Address reprint requests to: M. Fukui, M.D., Department of Neurosurgery, Neurological Institute, Faculty of Medicine, Kyushu University, 3-1-1 Maidashi, Higashi-ku, Fukuoka 812, Japan. 